\title{
Effect of Cooling Rate on Microstructure and Mechanical Properties of 20CrNi2MoV Steel
}

\author{
Jian Zhang ${ }^{1} \cdot$ Chang-Sheng $\mathrm{Li}^{1} \cdot$ Bin-Zhou $\mathrm{Li}^{1} \cdot$ Zhen-Xing $\mathrm{Li}^{1} \cdot$ Xue-Dong Pang ${ }^{2}$
}

Received: 21 October 2015/Revised: 8 December 2015/Published online: 11 March 2016

(C) The Chinese Society for Metals and Springer-Verlag Berlin Heidelberg 2016

\begin{abstract}
Thermo-mechanical process and continuous cooling process were carried out on $20 \mathrm{CrNi} 2 \mathrm{MoV}$ steel. Three cooling rates were implemented to optimize the mechanical properties. The microstructure evolution, precipitation behavior, and strengthening mechanisms were systematically investigated, and the fracture mechanisms were analyzed via combination of impact fracture morphologies and deflection-load curves. The experimental results indicate that the transformed microstructure of experimental steel is all complex consisting of granular bainitic ferrite and bainitic ferrite with dispersed martensite/austenite (M/A) constituents in the matrix at cooling rates of 13,21 , and $29^{\circ} \mathrm{C} / \mathrm{s}$. When the cooling rate increases, the grain of the steel is obviously refined. The sizes of the bainitic ferrite are 5.8, 4.7, and $3.1 \mu \mathrm{m}$ under cooling rates of 13,21 , and $29^{\circ} \mathrm{C} / \mathrm{s}$, respectively. The refinement of the bainitic ferrite plays a dominant role in strength increasing and also contributes to high crack propagation energy. However, the morphologies of M/A constituents obtained under different cooling rates contribute to different crack initiation energies and then affect the impact property.
\end{abstract}

KEY WORDS: 20CrNi2MoV steel; Microstructure; Cooling rate; Mechanical properties

\section{Introduction}

The well-known productions of high-strength toughness steel, in general, are performed by continuous cooling processes such as normalizing, quenching, and accelerate cooling [1-5]. The microstructure, therefore, is composed of a mixture of various kinds of transformation products such as the martensite, the bainite, and the ferrite [6,7]. Above all, the bainite plays an important role in improving strength and toughness $[8,9]$. However, the toughness of the bainitic transformation products is not always

Available online at http://link.springer.com/journal/40195.

Chang-Sheng Li

lics@ral.neu.edu.cn

1 State Key Laboratory of Rolling and Automation, Northeastern University, Shenyang 110819, China

2 Fushun Special Steel Co. Ltd, Fushun 110003, China monotonically dependent on the cooling rate and there is an optimum cooling rate for high toughness [10-13].

In recent years, the $20 \mathrm{CrNi} 2 \mathrm{MoV}$ steel has received significant attention because of applications in abrasion and impact resistant parts [14-16], and now it is widely employed in super impact resistance and abrasion parts for large machinery and equipment, e.g., high-speed railway train bearings. Also the bainite in the $20 \mathrm{CrNi} 2 \mathrm{MoV}$ steel with good strength and toughness is the subject of debate. And in the circumstance of energy saving and emission reduction all over the world, further reasonable application and improving the strength and toughness of the bainitic steel through the proper cooling process are becoming an urgently needed solution [17-20].

Accelerate cooling processing is a widely acknowledged approach to optimize strength-toughness combination through optimization of cooling parameters. In the present work, the effect of cooling rates on the microstructure and mechanical properties of $20 \mathrm{CrNi} 2 \mathrm{MoV}$ steel were investigated. Microstructure characteristics of the experimental steel 
with various cooling rates were clarified. The mechanism of brittleness and toughness based on cracks initiation and cracks propagation was systematically elucidated in details.

\section{Experimental}

The experimental steel ingot was produced by vacuum melting and electroslag remelting. The chemical composition of the steel in wt $\%$ was $0.2 \mathrm{C}, 0.58 \mathrm{Si}, 0.52 \mathrm{Mn}$, $0.008 \mathrm{P}, 0.003 \mathrm{~S} 0.35 \mathrm{Cr}, 0.24 \mathrm{Mo}, 1.45 \mathrm{Ni}, 0.38 \mathrm{Nb}$, and $0.59 \mathrm{~V}$. The ingot was forged into slabs with the dimensions of $60 \mathrm{~mm} \times 60 \mathrm{~mm} \times 180 \mathrm{~mm}$. The slab was heated to $1200{ }^{\circ} \mathrm{C}$ for $3 \mathrm{~h}$ to dissolve the microalloying elements and roughly rolled to $27 \mathrm{~mm}$ at $1100-1150{ }^{\circ} \mathrm{C}$. After air cooling to $890{ }^{\circ} \mathrm{C}$, followed by rolling using four passes on $\Phi 450 \mathrm{~mm}$ trial rolling mill, the slab was rolled to a plate of $12 \mathrm{~mm}$ thickness. The end temperature of finish rolling was controlled at $860{ }^{\circ} \mathrm{C}$. And then the plate was subjected to two-stage continuous cooling. In the first

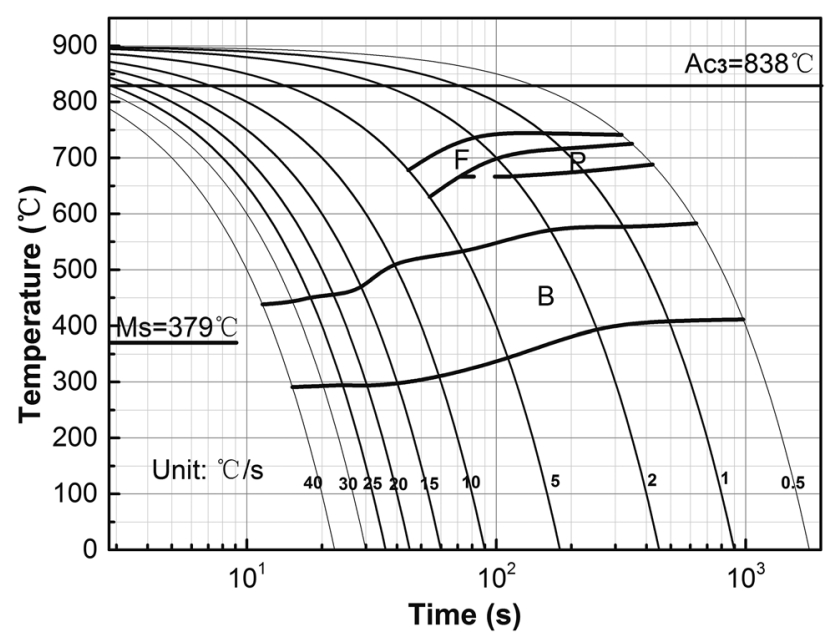

Fig. 1 Deformed austenite CCT diagram of the experimental steel stage, it was water-cooled at a rate of $10-30{ }^{\circ} \mathrm{C} / \mathrm{s}$ to final cooling temperature from 510 to $530{ }^{\circ} \mathrm{C}$. In the second stage, the plate was air-cooled to room temperature.

Metallographic specimens were mechanically polished and etched with a 4 vol\% nital and observed using Zeiss Ultra55 scanning electron microscope (SEM). The fracture surface of impact specimens was studied by an FEI Quanta 600 SEM. Transmission electron microscopy (TEM) studies were conducted using 3-mm-diameter thin foils, electropolished using a solution of 8 percent perchloric acid and alcohol and examined by FEI TecnaiG ${ }^{2}$ F20 TEM at an accelerating voltage of $200 \mathrm{kV}$. The chemical composition of the precipitates was determined by energydispersive X-ray spectroscopy (EDX).

Tensile specimens of dimensions of $5 \mathrm{~mm}$ in diameter and gauge of $25 \mathrm{~mm}$ in length were machined from the plates parallel to the rolling direction. The tensile tests were detected at room temperature with a crosshead speed of $1 \mathrm{~mm} / \mathrm{min}$ using a Shimadzu AG-X universal testing machine. Charpy V-notch impact tests were performed at $20{ }^{\circ} \mathrm{C}$ using standard specimens (dimensions: $10 \mathrm{~mm} \times 10 \mathrm{~mm} \times 55 \mathrm{~mm}$ ) with a $\mathrm{V}$-notch parallel to the rolling direction using Instron Dynatup 9200 series instrumented drop weight impact tester, consistent with ASTM E23 specification. All the strength and toughness values obtained here are an average of three measurements.

\section{Results and Discussion}

\subsection{The CCT Diagram}

Transformation temperatures were determined by tangents method. Draw tangent at catastrophe point in dilatometric curves and the point which tangent began to deviate from the curve is defined as critical point. Figure 1 shows the CCT diagram for the $20 \mathrm{CrNi} 2 \mathrm{MoV}$ steel. It can be seen from Fig. 1 that transformation of the ferrite and the bainite occurs for the experimental steel proceeds separately. That
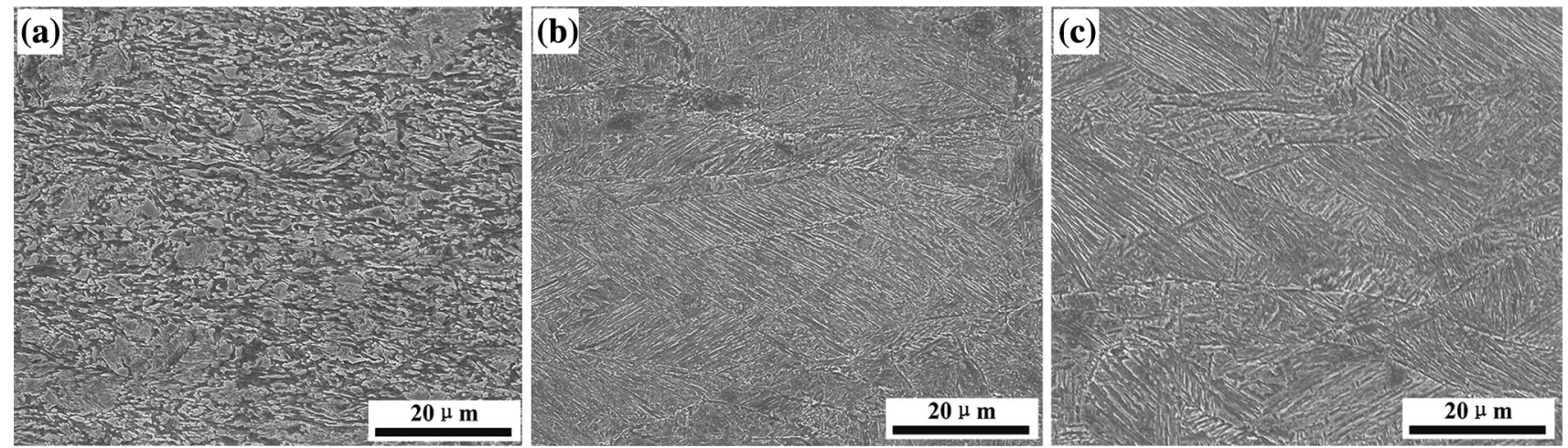

Fig. 2 SEM images of hot rolling test steels at different cooling rates: a $13{ }^{\circ} \mathrm{C} / \mathrm{s}, \mathbf{b} 21{ }^{\circ} \mathrm{C} / \mathrm{s}$, and $\mathbf{c} 29{ }^{\circ} \mathrm{C} / \mathrm{s}$ 

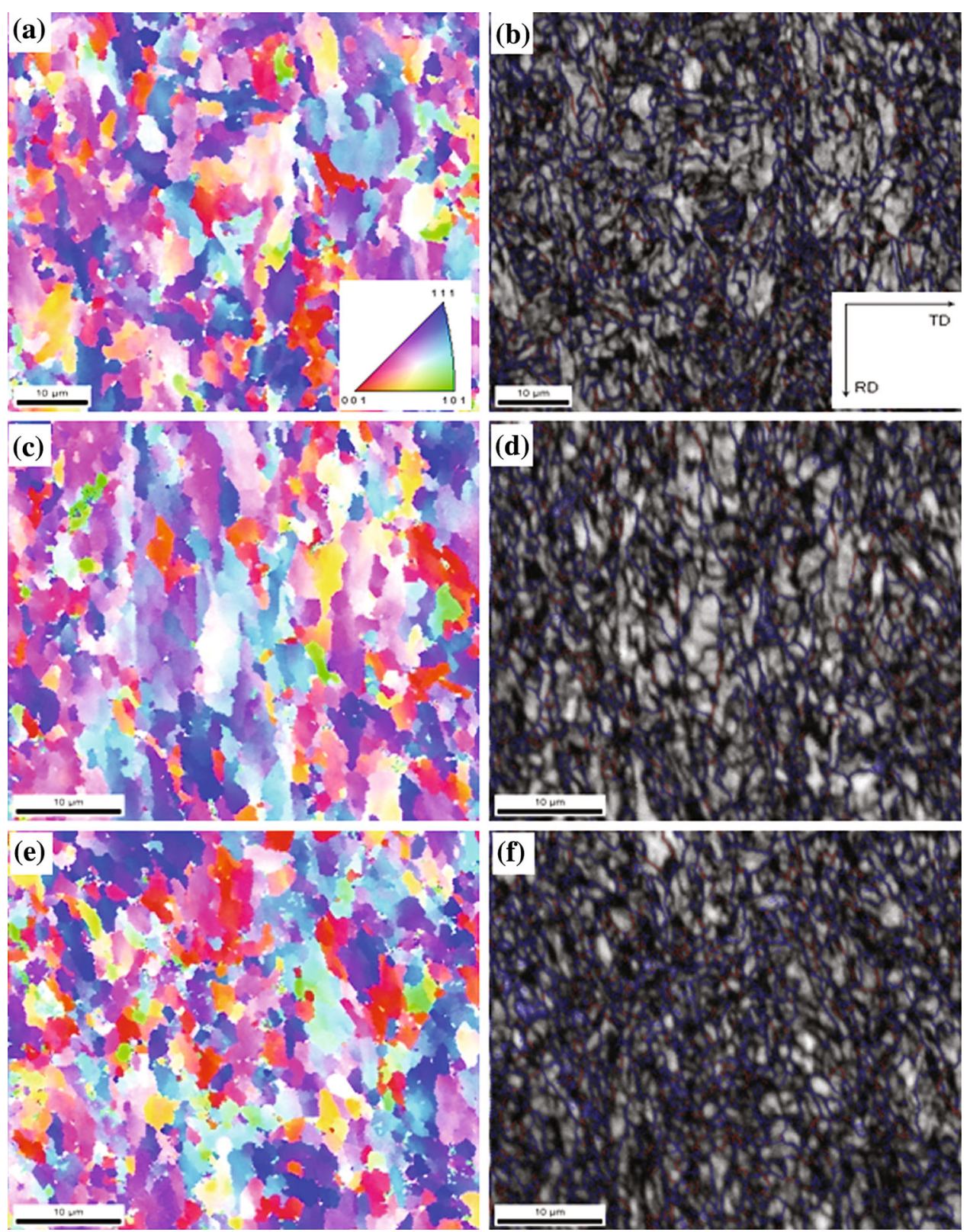

Fig. 3 Crystallographic characteristics of experimental steels analyzed by EBSD: a, c, e orientation image maps of experimental steel at different cooling rates 13,21 , and $29^{\circ} \mathrm{C} /$ s correspondingly; $\mathbf{b}, \mathbf{d}, \mathbf{f}$ image quality maps with the grain boundary mis-orientation distribution of experimental steel at different cooling rates 13,21 , and $29^{\circ} \mathrm{C} / \mathrm{s}$ correspondingly

is mainly because the steel is rich in $\mathrm{Cr}, \mathrm{Ni}, \mathrm{Mo}$, and $\mathrm{V}$ which can increase the stability of supercooled austenite and the incubation time of phase transformation.

According to the CCT curves in Fig. 1, if only the bainite structure of the experimental steel was expected to be obtained, the cooling rate needs to be $10-30{ }^{\circ} \mathrm{C} / \mathrm{s}$, so that transformation of the austenite to the ferrite and the martensite is restrained. In the current study, the cooling path after final hot rolling is indicated in red line in Fig. 1.

\subsection{Microstructure}

SEM micrographs of the experimental steel at different cooling rates are presented in Fig. 2, which reveal an evolution of the microstructure as the cooling rate increases from 13 to $29^{\circ} \mathrm{C} / \mathrm{s}$. As can be seen from Fig. 2, the transformed microstructure of experimental steel with different cooling rates is all complex consisting of the granular bainitic ferrite (GF), the bainitic ferrite (BF), and the 

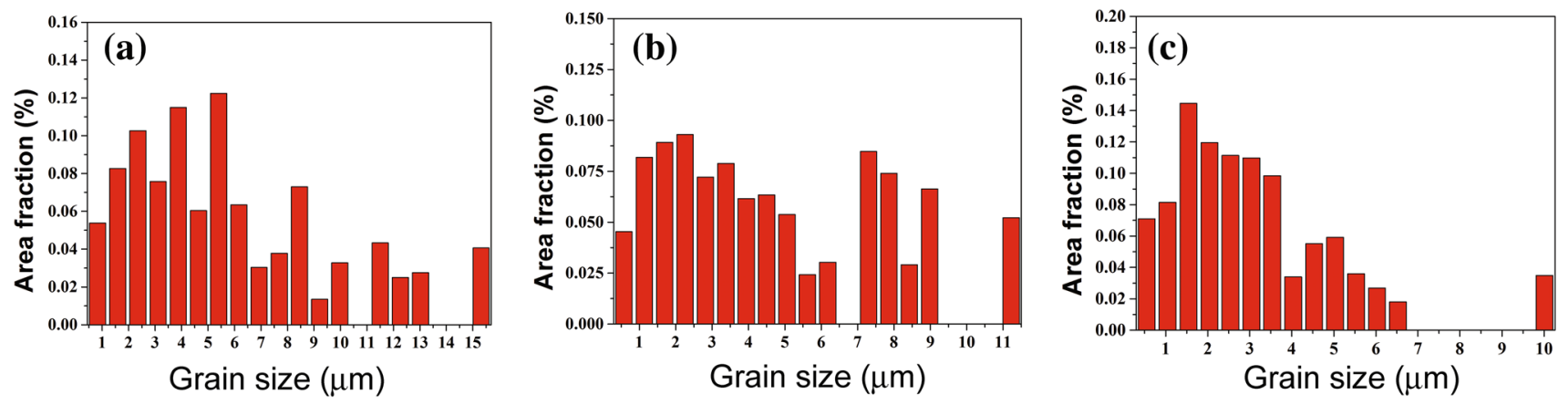

Fig. 4 Grain size distribution of experimental steels of different cooling rates: a $13{ }^{\circ} \mathrm{C} / \mathrm{s}$, b $21{ }^{\circ} \mathrm{C} / \mathrm{s}$, and c $29{ }^{\circ} \mathrm{C} / \mathrm{s}$
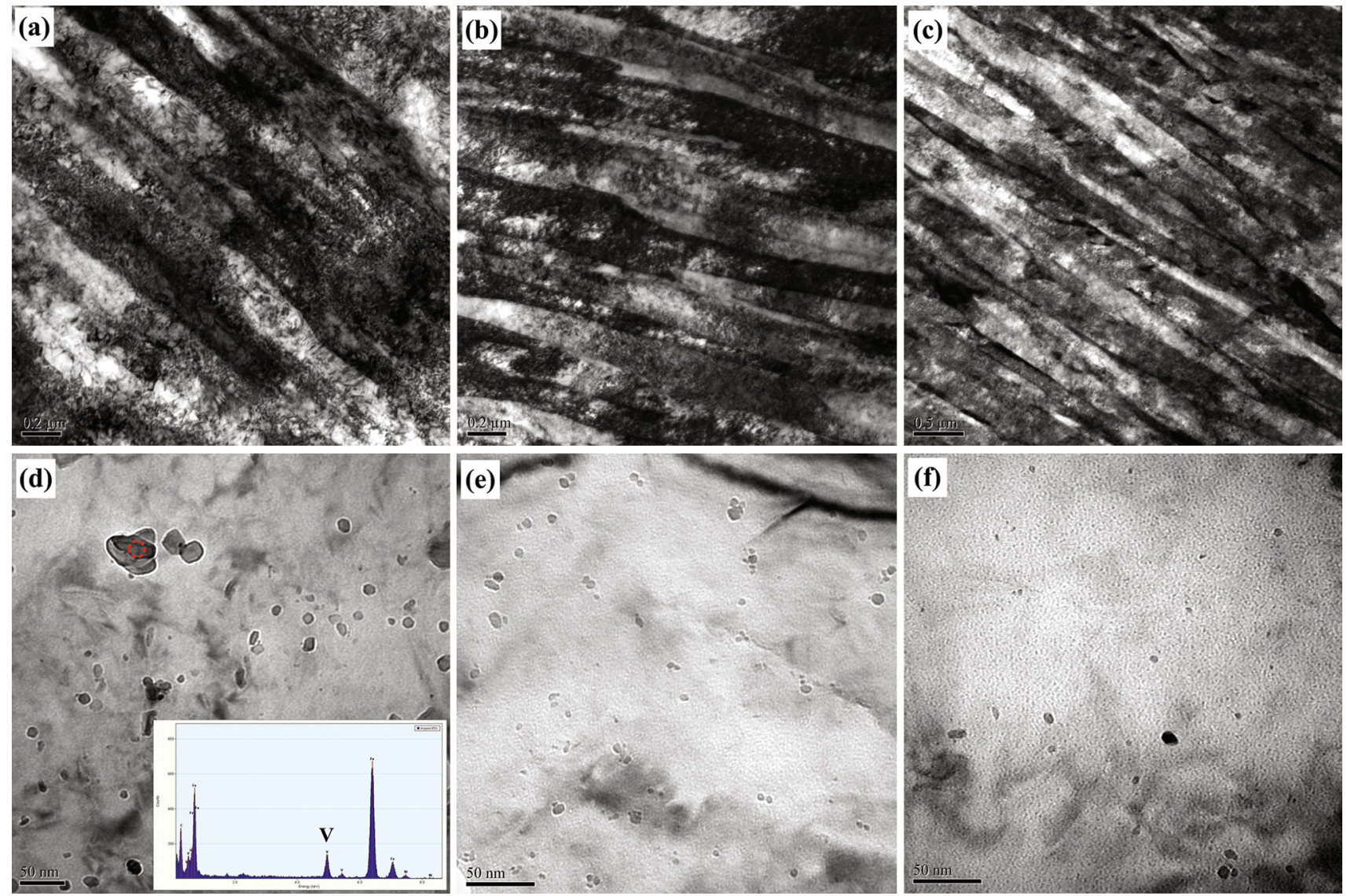

Fig. 5 TEM images of experimental steels at different cooling rates: a, d $13{ }^{\circ} \mathrm{C} / \mathrm{s}, \mathbf{b}$, e $21{ }^{\circ} \mathrm{C} / \mathrm{s}$, and $\mathbf{c}, \mathbf{f} 29^{\circ} \mathrm{C} / \mathrm{s}$

dispersed M/A constituents in the matrix where the martensite/austenite (M/A) is a significant structural characteristic in the microstructure of the bainite, and it generally exists in bainitic ferrite grain boundary or between neighboring ferrite laths. Here the magnification of the micrograph is slightly low and cannot clearly observe the independent martensite/austenite constituent. While in the following section of this paper, the martensite/austenite constituent has been observed by TEM.
Figure 3 shows EBSD results of experimental steel at different cooling rates. The colors in Figs. 3a, c, e represent the crystallographic orientation normal to the observed plane, as indicated by the stereographic triangle in the inset. Comparing Fig. 3a with $\mathrm{c}$, it can be found that the specimen with the cooling rate of $13{ }^{\circ} \mathrm{C} / \mathrm{s}$ presents more homogeneous and finer orientation distribution than that with the cooling time $21{ }^{\circ} \mathrm{C} / \mathrm{s}$ based on the distribution of orientation colors. As shown in Fig. 3a, the bainitic block 
with nearly the same trace direction in the morphology normally contains several laths in the crystallography for the specimen at the cooling rate of $13{ }^{\circ} \mathrm{C} / \mathrm{s}$. However, as the cooling rate increases, the size of the bainitic block refines and the boundary turns clear (shown in Fig. 3c) though it contains highly intricate, finer, and thinner of the laths in the morphology. When the cooling rate increases up to $29^{\circ} \mathrm{C} / \mathrm{s}$ (Fig. 3e), the austenite grain boundaries and deformation bands increase gradually and the ferrite transformation nucleation points increase which lead to the following fine grain forms.

In the boundary maps (Figs. 3b, d, f), the blue lines are the high misorientation grain boundaries higher than $15^{\circ}$, while the red lines stand for the low misorientation grain boundaries from $2^{\circ}$ to $15^{\circ}$. The grain boundaries of the block of the ferrite laths (e.g., the boundary of deformed austenite) exhibited high misorientation grain boundaries, and the laths inside the austenitic grains had low misorientation grain boundaries. The high misorientation grain boundaries efficiently arrest the propagation of cleavage microcracks, and it can be regarded as the effective grain size which controlled the growth of crack. The low misorientation boundaries cannot significantly deflect the cleavage cracks. However, it is the effective grain boundary contributes to the strength of the experimental steel.

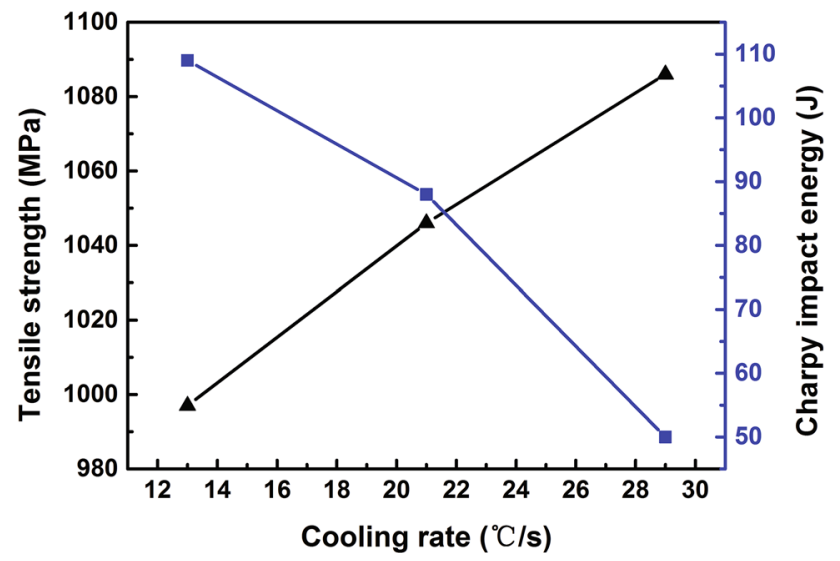

Fig. 6 Mechanical properties of the experimental steel under different cooling rates
And the grain size and width of the bainitic ferrite laths have significant impacts on the strength.

Figure 4 shows the grain size distribution of experimental steels on different cooling rates, the bainitic ferrite presents various nonequiaxed grain sizes distributed in a random manner, and grain refinement is obtained accompanied by increasing cooling rate. The sizes of bainitic ferrite are 5.8, 4.7, and $3.1 \mu \mathrm{m}$ under different cooling rates of 13,21 , and $29^{\circ} \mathrm{C} / \mathrm{s}$, respectively.

Figure 5 shows TEM micrographs of the experimental steel under different cooling rates. There is high density of dislocations in the matrix of the bainitic ferrite. The bainitic ferrite block consists of several parallel sub-plates with the width of $0.3,0.2$, and $0.17 \mu \mathrm{m}$ under different cooling rates of 13,21 , and $29^{\circ} \mathrm{C} / \mathrm{s}$, respectively, as shown in Fig. 5a-c. The morphology of M/A constituents in the bainite under different cooling rates is also investigated. There are three types of M/A constituents were observed: (1) rodlike M/A constituent with diameter of $0.5 \mu \mathrm{m}$ (Fig. 5b) under the cooling rate of $13{ }^{\circ} \mathrm{C} / \mathrm{s}$ reduces the stress concentration and then prevents cracks from propagation; (2) fine film M/A constituent distributes between the ferrite laths with length of $0.5 \mu \mathrm{m}$ and width of $50 \mathrm{~nm}$ under the cooling rate of $21{ }^{\circ} \mathrm{C} / \mathrm{s}$ (Fig. 5c); and (3) ultrafine film or acicular M/A constituent distributes between the fine ferrite laths with the diameter of $0.15 \mu \mathrm{m}$ (Fig. 5c) under the cooling rate of $29^{\circ} \mathrm{C} / \mathrm{s}$.

Figures $5 \mathrm{~d}$, e, and $\mathrm{f}$ show the precipitates morphologies of the steel under different cooling rates. The energy spectrum analysis is shown in Fig. 5d (insert), and the result illustrates that the precipitates are the compounds of $\mathrm{V}(\mathrm{C}, \mathrm{N})$. The particle size of the precipitates is about $25 \mathrm{~nm}, 15 \mathrm{~nm}$, and $8 \mathrm{~nm}$ under the cooling rate of 13, 21, and $29{ }^{\circ} \mathrm{C} / \mathrm{s}$, respectively. With the increase in the cooling rate, the particle size and amounts of the precipitates decrease.

\subsection{Mechanical Properties}

The mechanical properties of the experimental steels under different cooling rates are shown in Fig. 6. The results are
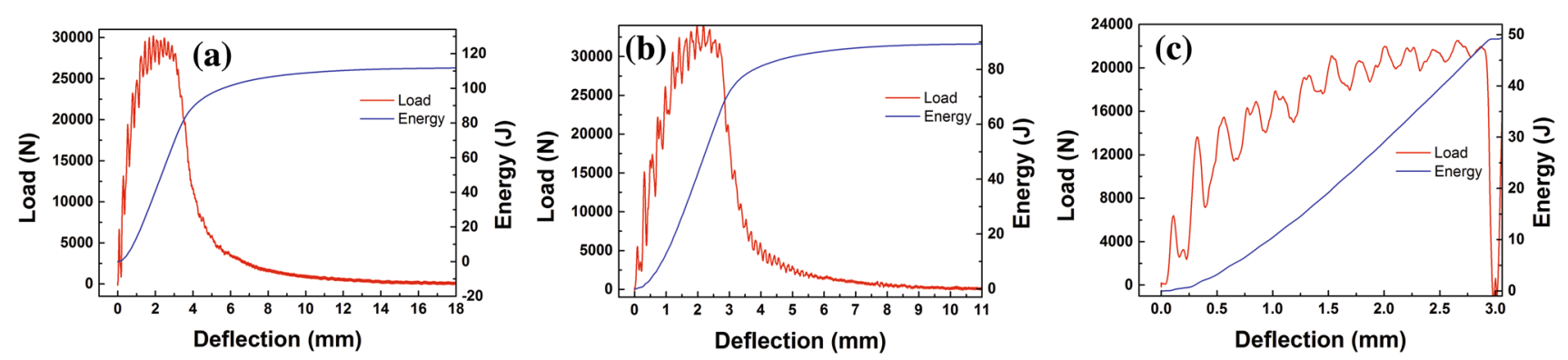

Fig. 7 Deflection-load and deflection-energy plots of impact specimens: a $13{ }^{\circ} \mathrm{C} / \mathrm{s}$, b $21{ }^{\circ} \mathrm{C} / \mathrm{s}$, and c $29{ }^{\circ} \mathrm{C} / \mathrm{s}$ 



Fig. 8 SEM images of the impact fracture: a, d $13{ }^{\circ} \mathrm{C} / \mathrm{s}$, b, e $21{ }^{\circ} \mathrm{C} / \mathrm{s}$, and $\mathbf{c}, \mathbf{f} 29^{\circ} \mathrm{C} / \mathrm{s}$

also summarized as follows. Under the cooling rate of $13{ }^{\circ} \mathrm{C} / \mathrm{s}$, the yield strength, the tensile strength, and elongation to fracture of the steel were $803,997 \mathrm{MPa}$, and $18.4 \%$, respectively. The impact absorbed energy of Charpy specimens tested at room temperature was $109 \mathrm{~J}$. Under the cooling rate of $21{ }^{\circ} \mathrm{C} / \mathrm{s}$, both the yield strength and the tensile strength were increased to 879 and $1046 \mathrm{MPa}$, respectively, while the elongation to fracture was decreased to $16.6 \%$, and the impact absorbed energy at room temperature was reduced to $88 \mathrm{~J}$. Under the cooling rate of $29{ }^{\circ} \mathrm{C} / \mathrm{s}$, both yield strength and the tensile strength were slightly increased to 894 and $1086 \mathrm{MPa}$, while the elongation to fracture was sharply decreased to $13.6 \%$ and the impact absorbed energy at room temperature only reached to $50 \mathrm{~J}$. In general, the combination of strength and ductility of experimental steel decreases with the increase in cooling rate.

Figure 7 shows the deflection-load and deflection-energy plots of impact specimens. The total absorbed energy can be divided into $E_{1}$-crack initiation energy (including $E_{\mathrm{e}}$-elastic deformation energy and $E_{\mathrm{p}}$-plastic deformation energy), $E_{2}$-stable crack propagation energy, and $E_{3}$-unstable fracture energy.

$E_{1}$ has a relationship with the initiation and propagation of the plastic shear zone and represents the difficulty of initiating the crack. As shown in Figs. 7a-c, the loads all reach peak value at the similar deflection $(\sim 2.7 \mathrm{~mm})$ in the three deflection-load plots, and the crack initiation energy is about $53 \mathrm{~J}$.

$E_{2}$ is connected with the propagation of the stable crack, namely the tearing energy of the fracture fibrous zone. Once the unstable crack begins to develop, the stable cracks stop propagating. Therefore, $E_{2}$ reflects the difficulty of initiating and prorogating the unstable crack. $E_{3}$ represents the fracture energy of the hardened zone, which usually depends on the restraint of the unstable crack. Under the cooling rate of $13{ }^{\circ} \mathrm{C} / \mathrm{s}$, the total impact absorbed energy of $109 \mathrm{~J}$ at room temperature is separated into the crack initiation energy, stable crack propagation energy, and unstable fracture energy which are 53, 39, and $17 \mathrm{~J}$, respectively, and for the steel under the cooling rate of $21^{\circ} \mathrm{C} / \mathrm{s}$ are 51,21 , and 16 , respectively. While under the cooling rate of $29{ }^{\circ} \mathrm{C} / \mathrm{s}$, there is only the crack initiation energy about $50 \mathrm{~J}$ and the crack propagation process was disappeared. Thus, similar crack initiation energies were obtained in the steel under the cooling rate of 13,21 , and $29^{\circ} \mathrm{C} / \mathrm{s}$, while the crack propagation energy of the steel under the cooling rate of $13^{\circ} \mathrm{C} / \mathrm{s}$ was significantly higher than the steel of $21^{\circ} \mathrm{C} / \mathrm{s}$. The refinement of the bainitic ferrite plays a dominant role in the formation mechanism of crack and contributes to high crack propagation energy, while the morphologies of M/A constituents obtained under different cooling rates contribute to different crack initiation energies. Furthermore, the loads of the 
steel under the cooling rate of 13 and $21{ }^{\circ} \mathrm{C} / \mathrm{s}$ decrease gradually after attaining the peak, whereas in the steel under the cooling rate of $29^{\circ} \mathrm{C} / \mathrm{s}$, the load decreases sharply, and the brittle fracture characteristic is observed.

Figure 8 shows the SEM micrographs of the impact fracture at room temperature. Except for the V-notch zone, the fracture surface can be divided into three zones, including the fibrous zone, the radial zone (zone extending outwards), and the shear lip zone. During the Charpy impact process, the fibrous zone can absorb higher impact energy, and its area proportion of the sectional area reflects the toughness value. By observing the macroscale fracture, as shown in Figs. 8a-c, the surface of the steel under the cooling rate of 13 and $21{ }^{\circ} \mathrm{C} / \mathrm{s}$ consists of several distinct regions, while the steel under the cooling rate of $29^{\circ} \mathrm{C} / \mathrm{s}$ has hardly any fibrous zone. The steel under the cooling rate of $13{ }^{\circ} \mathrm{C} / \mathrm{s}$ represents the maximum area of fibrous zone consisting of elongated small dimples (Fig. 8a). The fibrous zone of the steel under the cooling rate of $21{ }^{\circ} \mathrm{C} / \mathrm{s}$ comprises of large and flat dimples (Fig. 8b). Compared to Fig. 8a, as the cooling rate increases, the impact energy of the steel under the cooling rate of $21{ }^{\circ} \mathrm{C} / \mathrm{s}$ is reduced. However, large cleavage facets exist in the radial zone of the steel under the cooling rate of $29^{\circ} \mathrm{C} / \mathrm{s}$ (Fig. 8c), which can absorb negligible impact energy, and thus, it presents an apparent brittle fracture characteristics.

\section{Conclusions}

1. The microstructure of $20 \mathrm{CrNi} 2 \mathrm{MoV}$ steel consists of granular bainitic ferrite and bainitic ferrite with dispersed martensite/austenite constituents in the matrix. When the cooling rate increases, the ferrite grain is obviously refined. The bainitic ferrite size is 5.8, 4.7, and $3.1 \mu \mathrm{m}$ under cooling rates of 13,21 , and $29^{\circ} \mathrm{C} / \mathrm{s}$, respectively.

2. With increasing cooling rate, the yield strength and the tensile strength of the $20 \mathrm{CrNi} 2 \mathrm{MoV}$ steel increase, while the ductile decreases. The yield strength is 803 , 879 , and $894 \mathrm{MPa}$, the tensile strength is 997,1046 , and $1086 \mathrm{MPa}$, and the elongation to fracture is 18.4 , 16.6 , and $13.6 \%$, under the cooling rate of 13,21 , and $29{ }^{\circ} \mathrm{C} / \mathrm{s}$, respectively. In general, the steel exhibits better strength and ductility which satisfy the expected requirements when the cooling rate is less than $21^{\circ} \mathrm{C} / \mathrm{s}$.

3. The refinement of the bainitic ferrite plays a dominant role in the formation mechanism of the crack and contributes to high crack propagation energy, while the morphologies of M/A constituents obtained under different cooling rates contribute to different crack initiation energies. Under the cooling rate of $13{ }^{\circ} \mathrm{C} / \mathrm{s}$, initiation energy is $53 \mathrm{~J}$, stable crack propagation energy is $39 \mathrm{~J}$, and unstable fracture energy is $17 \mathrm{~J}$. Under the cooling rate of $21{ }^{\circ} \mathrm{C} / \mathrm{s}$, initiation energy is $51 \mathrm{~J}$, stable crack propagation energy is $21 \mathrm{~J}$, and unstable fracture energy is $16 \mathrm{~J}$. While the cooling rate is $29^{\circ} \mathrm{C} / \mathrm{s}$, there is only the crack initiation energy about $50 \mathrm{~J}$ and the crack propagation process is disappeared.

4. Increasing cooling rate is the very effective approach for increasing the great strength but decreasing the toughness, whereas when the cooling rate is controlled to $20{ }^{\circ} \mathrm{C} / \mathrm{s}$, the experimental steel would exhibit better the strength and the toughness properties, which satisfy the expected requirements.

Acknowledgments This work was financially supported by the National High Technology Research and Development Program of China (No. 2012AA03A503), the National Natural Science Foundation of China (Nos. 51174057 and 51274062) and Research Fund for the Doctoral Program of Higher Education of China (No. 20130042110040).

\section{References}

[1] M.C. Zhao, K. Yang, Y. Shan, Mater. Sci. Eng. A 335, 14 (2002)

[2] X. Kong, L. Lan, Z. Hu, B. Li, T.Z. Sui, J. Mater. Process. Technol. 217, 202 (2015)

[3] Z.X. Li, C.S. Li, B.Z. Li, Y.Q. Ma, T. Li, Mater. Sci. Technol. 31, 722 (2015)

[4] Z.Y. Huang, Q. Shi, F.Q. Chen, Y.F. Shi, Acta Metall. Sin. (Engl. Lett.) 27, 421 (2014)

[5] P.A. Manohar, T. Chandra, ISIJ Int. 38, 766 (1998)

[6] X.J. Di, L. Cai, X.X. Xing, C.X. Chen, Z.K. Xue, Acta Metall. Sin. (Engl. Lett.) 28, 883 (2015)

[7] H. Ohtani, S. Okaguchi, Y. Fujishiro, Y. Ohmori, Mater. Trans. A 21, 877 (1990)

[8] D.V. Edmonds, R.C. Cochrane, Mater. Trans. A 21, 1527 (1990)

[9] F.G. Caballero, H. Roelofs, S. Hasler, C. Capdevila, J. Chao, J. Cornide, C.G. Mateo, Mater. Sci. Technol. 28, 95 (2012)

[10] K.D. Kim, L.X. Du, C.R. Gao, Acta Metall. Sin. (Engl. Lett.) 28, $692(2015)$

[11] K. Poorhaydari, B.M. Patchett, D.G. Ivey, Mater. Sci. Eng. A 382, 435 (2006)

[12] M. Chang, H. Yu, Int. J. Min. Metall. Mater. 20, 427 (2013)

[13] C.S. Li, B. Ma, T. Li, Acta Metall. Sin. (Engl. Lett.) 27,422 (2014)

[14] R. Huang, N.B. Lu, Y.M. Liu, Hot Work. Technol. 43, 176 (2014). (in Chinese)

[15] W.H. Xue, Z.C. Li, Mater. Heat Treat. 40, 173 (2011). (in Chinese)

[16] M.L. Zhu, F.Z. Xuan, Mater. Des. 65, 707 (2015)

[17] S.W. Thompson, D.J. Colvin, G. Krauss, Metall. Mater. Trans. A 27, 1557 (1996)

[18] M.P. Rao, V.S. Sarma, S. Sankaran, Mater. Sci. Eng. A 568, 171 (2013)

[19] I.A. Yakubtsov, P. Poruks, J.D. Boyd, Mater. Sci. Eng. A 480, 109 (2008)

[20] Y. Furuya, Scr. Mater. 58, 1014 (2008) 